\title{
DAMPAK VARIABEL MAKROEKONOMI PADA VOLATILITAS PASAR MODAL SYARIAH INDONESIA: PENDEKATAN MODEL ERROR CORRECTION
}

\author{
Setyo Tri Wahyudi ${ }^{1}$ \\ Rihana Sofie Nabella ${ }^{2}$
}

Fakultas Ekonomi dan Bisnis Universitas Brawijaya, Jawa Timur, Indonesia ${ }^{1,2}$

Email:wsetyotri@gmail.comํㅗ.sofierihana@gmail.com²

\begin{abstract}
The Impact of Macroeconomic Variables on The Volatility of Indonesian Sharia Capital Market: Error Correction Model Approach. Indonesia's sharia capital market continues to develop and become an alternative investment. Compared to conventional capital markets, sharia capital markets are believed to be stronger against crises, changes in economic fundamentals and financial market shocks. This study aims to analyze the effect of macroeconomic variables on Indonesia Sharia Stock Index. This research uses Error Correction Model (ECM) method. The results of this study are the rising exchange rate and world crude oil price will decrease Sharia Index of Indonesia Shares (ISSI), in the long run and short term increase of BI Rate will increase Sharia Index of Indonesia (ISSI) and inflation rate does not affect Indonesia Sharia Index (ISSI).
\end{abstract}

Keywords: Indonesian Sharia Capital Market; Macroeconomics variables.

Abstrak: Dampak Variabel Makroekonomi pada Volatilitas Pasar Modal Syariah Indonesia: Pendekatan Model Error Correction. Pasarmodal syariah Indonesia terus mengalami perkembangan dan menjadi alternatif investasi. Dibandingkan dengan pasar modal konvensional, pasar modal syariah diyakini lebih kuat terhadap krisis, perubahan fundamental ekonomi dan goncangan pasar keuangan. Penelitian ini bertujuan untuk menganalisis pengaruh variabel makroekonomi terhadap Indeks Saham Syariah Indonesia. Penelitian ini menggunakan metode Error Correction Model (ECM). Hasil penelitian ini adalah naiknya kurs dan harga minyak mentah dunia akan menurunkan Indeks Saham Syariah Indonesia (ISSI), dalam jangka panjang dan jangka pendek kenaikan BI Rate akan menaikkan Indeks Saham Syariah Indonesia (ISSI) dan naiknya tingkat inflasi tidak mempengaruhi Indeks Saham Syariah Indonesia (ISSI).

Kata kunci : Indeks Harga Saham Syariah (ISSI); variabel makroekonomi. 


\section{PENDAHULUAN}

Dalam perekonomian, pasar modal investor syariah setelah adanya unit menjadi bagian penting dalam mendukung pengembangan syariah (Februari 2014) terus ekonomi suatu negara, termasuk di Indonesia. mengalami peningkatan hingga pada tahun Peran penting pasar modal sebagai lembaga perantara yang mempertemukan kepentingan pemberi modal dan pencari modal. Alokasi dana Terjadinya kesepakatan antara kedua pihak tersebut, menghasilkan terciptanya efisiensi alokasi dana yang memungkinkan diperolehnya alternatif investasi dengan return optimal (Tandelilin, 2001).

Munculnya pasar modal syariah sebagai bagian dari sistem pasar modal juga berkontribusi dalam memberikan alternatif investasi dan saluran pembiayaan serta mobilisasi sumber daya ekonomi. Pasar modal syariah di Indonesia mengalami perkembangan yang ditunjukkan oleh naiknya jumlah investor saham syariah pada Gambar 1.

Terlihat pada Gambar 1, jumlah 2017 mencapai 18.330. Hal tersebut didukung oleh meningkatnya pangsa pasar investor syariah terhadap total investor secara signifikan. Berdasarkan data Otoritas Jasa Keuangan, pada tahun 2017 pangsa pasar investor syariah mencapai 3,1\% dari investor total, dimana pada tahun 2014 hanya sebesar $0,7 \%$ dari investor total.

Dibandingkan dengan pasar modal konvensional, pasar modal syariah diyakini lebih kuat terhadap krisis, perubahan fundamental ekonomi dan goncangan pasar keuangan. Goncangan tersebut diakibatkan oleh ekspektasi terhadap masa depan dari faktor makro dan mikro di suatu negara baik secara rasional atau adaptif pada fundamental ekonomi yang dapat

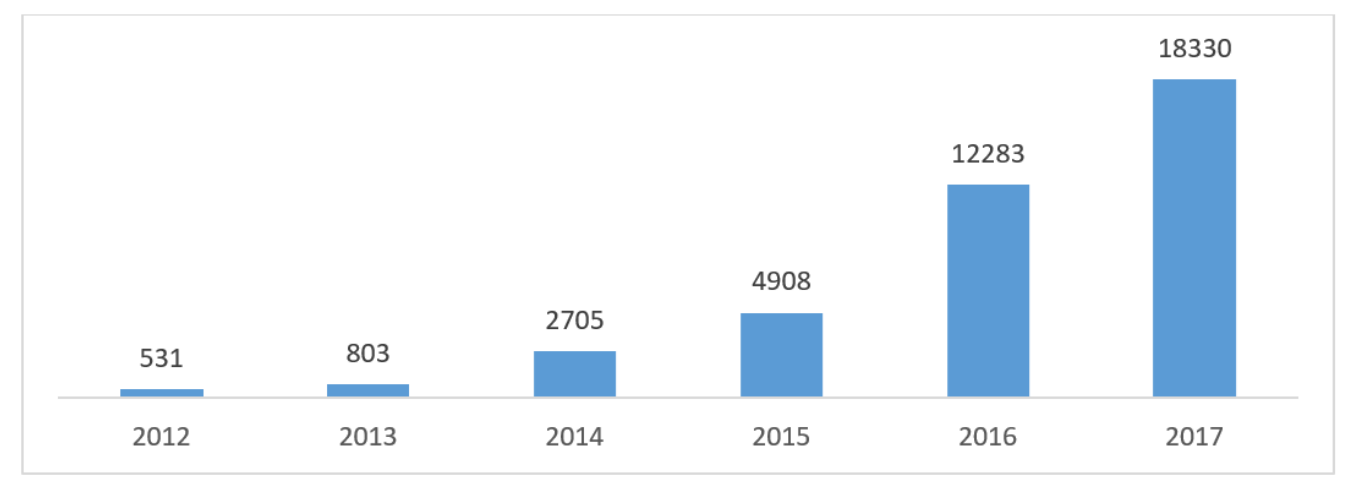

Sumber : OJK, Data Diolah 2018 
diprediksi atau tidak dapat diprediksi. Berbagai bunga dan harga saham memberikan arah faktor penentu perkembangan indeks Syariah, seragam yakni memiliki hubungan negatif. seperti ditunjukkan oleh Syahrir (1995) dibagi Kenaikan suku bunga akan meningkatkan dalam faktor moneter dan faktor internal. Disisi tingkat nominal bebas risiko dan pada saat yang moneter meliputi SBI Syariah, inflasi, jumlah sama akan meningkatkan tingkat diskonto. uang beredar (JUB), serta nilai tukar, sementara Hamrita \& Trifi (2011) menyatakan bahwa faktor internal meliputi kondisi ekonomi, kenaikan suku bunga mengurangi nilai sekarang politik, keamanan, serta kebijakan pemerintah. dari pendapat deviden masa depan yang akan Berbagai studi mengenai hubungan menekan harga saham. Pengaruh tingkat suku antara inflasi dan harga saham memberikan hasil bunga terhadap pasar saham syariah dapat berbeda, hubungan positif (Thaker et al., 2009) dijelaskan dalam keputusan membelanjakan ataupun negatif (Pasaribu \& Firdaus, 2013). lebih banyak uang atau menyimpan uang dalam Meningkatnya tingkat inflasi mengakibatkan bentuk portofolio tabungan atau portofolio kebijakan ekonomi yang ketat, sehingga membuat tingkat bebas risiko nominal (free risk nominal rate) akan meningkat dan pada saat yang sama, tingkat diskonto akan meningkat dan menciptakan hasil yang sama dengan harga saham syariah. Salah satu penyebab inflasikarena adanya penurunan daya beli uang (Tandelilin, 2010). Selain itu, jika terjadi kenaikan inflasi tinggi dan bersifat tidak menentu (uncertainty) akan berdampak pada meningkatnya resiko investasi serta melemahnya mata uang domestik (Ardana, 2016).

Berbeda dengan hubungan inflasi dengan pasar saham, hubungan antara suku baik serta akan menentukan iklim investasi lain seperti pasar saham syariah (Malini \& Jais, 2014). Selain itu, penentuan suku bunga tabungan dan deposito mengacu pada BI rate yang mengcover pergerakan inflasi dan nilai tukar (Widoatmodjo, 2005).

Pengklasifikasian perusahaan multinasional dalam pasar saham syariah di Indonesia turut berkontribusi pada penentuan keterkaitan harga saham dan nilai tukar. Kondisi depresiasi maupun apreasiasi nilai tukar sebagai cerminan kondisi berubahnya perilaku masyarakat dalam memegang uang. Semakin menguat nilai tukar Rupiah maka kinerja di pasar uang juga semakin 
dalam pasar modal Indonesia. Tentunya, hal tersebut akan menjadi referensi bagi investor dalam memutuskan berinvestasi di bursa saham Indonesia, khususnya terkait resiko (Robert, 1997). Kondisi serupa juga ditunjukkan dalam kasus bursa saham di Malaysia (Vejzagic \& Zarafat, 2013).

Terakhir, harga minyak dunia yang diukur dari harga spot pasar minyak dunia, memiliki hubungan dengan pasar saham. Harga minyak dan harga saham memiliki hubungan yang berbeda. Hubungan positif dihasilkan jika guncangan yang terrjadi pada harga minyak dicerminkan dalam permintaan agregat, sebaliknya, akan memiliki berhubungan negatif jika harga minyak mencerminkan perubahan penawaran (Malini \& Jais, 2014). Selain itu, harga saham merespon secara asimetris terkait perubahan harga minyak. Maksudnya, tingginya harga minyak dapat dikaitkan dengan harga saham yang rendah, sebaliknya rendahnya harga minyak tidak dapat dikaitkan dengan harga saham yang tinggi.

\section{METODE PENELITIAN}

Penelitian ini menggunakan pendekatan kuantitatif dengan memanfaatkan data-data data sekunder bulanan untuk periode tahun 2013 hingga 2017. Indeks Saham Syariah Indonesia (ISSI) sebagai variabel terikat, sedangkan variabel bebasmnya meliputi inflasi, nilai tukar (kurs), BI-Rate dan harga minyak dunia. Sumber data inflasi, nilai tukar, dan BI-Rate dari Bank Indonesia. Sedangkan data harga minyak dunia diperoleh dari situs www.indexmundi.com, data Indeks Saham Syariah Indonesia (ISSK) diperoleh dari OJK. Data bulanan memiliki kecenderungan berfluktuasi serta menghasilkan ketikaseimbangan, oleh karena itu dipilih Error Correction Model (ECM) sebagai metode analisis. Selain itu, alasan digunakan metode ECM adalah bahwa metode ini dapat melihat pengaruh jangka pendek dan jangka panjang dari variabel bebasnya.

Persamaan estimasi jangka panjang dalam penelitian ini adalah:

$L N_{-} I S S I_{t}=\alpha+\beta_{I} I N F_{t}+\beta_{2} L N_{-} K U R S_{t}+\beta_{3}$ BIRATE $_{t}+$

$$
\beta_{4} L N_{-} H M M D_{t}+e_{t}
$$

Selanjutnya, persamaan tersebut diestimasi menggunakan metode Error Correction Model (ECM). Secara umum model ECM jangka pendek sebagai berikut:

$D L N_{-} I S S K_{t}=\alpha+\beta_{1} D I N F_{t}+\beta_{2} D L N_{-} K U R S_{t}+\beta_{3} D B I R A T E_{t}$

$$
+\beta_{4} D L N_{-} H M M D_{t}+\gamma E C T+e_{t}
$$




\section{HASIL DAN PEMBAHASAN}

Berikut ini adalah hasil dari tahap pengujian yang dilakukan yaitu terdiri dari uji stasioneritas data dan uji derajad integrasi, uji kointegrasi Eagle-Granger, estimasi ECM Engle Granger dan pengujian asumsi klasik. Uji Stasioneritas Data dan Uji Derajat Integrasi. Pada tahap awal, dilakukan pengujian stasioneritas data menggunakan uji ADF (Augmented Dickey Fuller). Kriteria yang digunakan didasarkan pada nilai prob Schward Info Criterion (SIC). Suatu data dikatakan stasioner jika memiliki nilai prob kurang dari $\alpha(0,05)$ sebaliknya dikatakan tidak stasioner.

Tabel 1. Hasil Pengujian Stasioner pada Derajat Level

\begin{tabular}{lcl}
\hline \multicolumn{1}{c}{ Variabel } & Prob & \multicolumn{1}{c}{ Keterangan } \\
\hline ln_ISSI & 0.8199 & Tidak Stasioner \\
Inflasi & 0.3219 & Tidak stasioner \\
ln_Kurs & 0.1908 & Tidak stasioner \\
BI_Rate & 0.9754 & Tidak stasioner \\
ln_HMMD & 0.1310 & Tidak stasioner \\
\hline
\end{tabular}

Sumber: Lampiran Olah Data, 2020

Berdasarkan Tabel 1 menunjukkan bahwa uji stasioner pada tingkat level menghasilkan adanya ketidakstsioneran pada seluruh variabel. Oleh karena itu perlu dilakukan transformasi data (differencing) dengan menurunkan data menjadi first difference (I(1)). Pelunya data diturunkan ke first difference untuk mendapatkan data yang stasioner. Selain itu, untuk menghindari terjadinya regresi lancung (spurious regression).

Tabel 2. Hasil Pengujian Stasioner pada First Difference

\begin{tabular}{lcc}
\hline \hline \multicolumn{1}{c}{ Variabel } & $\begin{array}{l}\text { Nilai } \\
\text { Prob }\end{array}$ & Keterangan \\
\hline In_ISSI & 0.0000 & Stasioner \\
Inflasi & 0.0000 & Stasioner \\
ln_Kurs & 0.0000 & Stasioner \\
BI_Rate & 0.0000 & Stasioner \\
ln_HMMD & 0.0000 & Stasioner \\
\hline
\end{tabular}

Sumber: Lampiran Olah Data, 2020

Berdasarkan Tabel 2 dapat dilihat bahwa setelah dilakukan penurunan pada first difference diperoleh kesimpulan bahwa semua variabel telah stasioner pada derajat tersebut

Uji Kointegrasi. Setelah semua variabel telah stasioner pada derajat yang sama, kemudian dilanjutkan dengan pengujian kointegrasi. Tujuan uji kointegrasi untuk mengetahui apakah terjadi hubungan jangka panjang yang stabil antara variabel-variabel yang terintegrasi pada derajat yang sama. Adanya hubungan jangka Panjang ditunjukkan oleh variabel yang terkointegrasi.

Berdasarklan Tabel 3, diketahui bahwa semua variabel dalam penelitian memiliki pengaruh signifikan pada indeks harga saham Syariah Indonesia, namun dengan besaran dan tingkat signifikasi yang berbeda. Khusus variabel inflasi, jika digunakan tingkat kepercayaan $(\alpha)$ 
Tabel 3.

\section{Hasil Estimasi dalam Jangka Panjang}

\begin{tabular}{lcccc}
\hline \multicolumn{5}{c}{ Variabel Terikat: ISSK } \\
\hline \multicolumn{1}{c}{ Variabel Bebas } & Coefficient & Std. Error & t-Statistic & Prob. \\
\hline Inflasi & -0.012565 & 0.006711 & -1.872235 & 0.0665 \\
ln_Kurs & 0.789750 & 0.2233613 & 3.531765 & 0.0008 \\
BI Rate & -0.052428 & 0.009220 & -5.686437 & 0.0000 \\
ln_HMMD & -0.041923 & 0.020078 & -2.088022 & 0.0414 \\
C & 8.174991 & 2.040140 & 4.007073 & 0.0002 \\
\hline Prob (F-Statistic) & & 0.000000 & \\
R-squared & & 0.661898 & \\
\hline
\end{tabular}

Sumber: Lampiran Olah Data, 2020

5 persen (0.05), maka variabel inflasi tidak 33.81\% dijelaskan oleh error, dalam hal ini berpengaruh secara signifikan, namun jika variabel di luar penelitian.

digunakan kepercayaan $(\alpha) 10$ persen $(0.1), \quad$ Nilai residual dalam uji jangka Panjang maka dalam jangka panjang variabel inflasi kemudian lakukan pengujian stasioneritas memiliki pengaruh signifikan pada indeks harga menggunakan uji ADF. Tujuannya untuk saham Syariah Indonesia. mengetahui apakah persamaan tersebut telah

Ketiga variabel lainnya yakni KURS, terkointegrasi atau memiliki keseimbangan BI_RATE dan harga minyak mentah dunia dalam jangka panjang. Selanjutnya, residual memiliki nilai prob $<$ nilai $\alpha(0.05)$, artinya tersebut akan digunakan dalam estimasi dalam dalam jangka Panjang ketiga variabel tersebut jangka pendek sebagai variabel Error Correction berpengaruh terhadap Indeks Saham Syariah Term (ECT).

Indonesia. Sementara, nilai R-squared model relatif tinggi yakni 0.661898 , artinya dalam jangka panjang kemampuan variabel independen dalam mempengaruhi Indeks Saham Syariah Indonesia sebesar $66,19 \%$, sedangkan sisanya
Berdasarkan Tabel 4, terlihat bahwa nilai prob lebih kecil daripada nilai $\alpha$. Hasil tersebut menyatakan bahwa residual dalam jangka panjang telah stasioner di tingkat level

Estimasi Error Correction Model.

Tabel 4.

\section{Hasil Pengujian Stasioner Residual pada Derajat Level}

\begin{tabular}{cccc}
\hline Variabel & Nilai Prob & $\boldsymbol{\alpha}(\mathbf{0 , 0 5})$ & Keterangan \\
\hline RESID01 & 0.0089 & 0.05 & Stasioner \\
\hline
\end{tabular}


Karakteristik unik dalam model ECM adalah $\alpha(0.05)$, artinya bahwa dalam jangka pendek, adanya Error Correction Term (ECT). seluruh variabel tidak berpengaruh terhadap Pentingnya nilai koefisien ECT dalam model Indeks Saham Syariah Indonesia. Hal tersebut dapat digunakan untuk untuk mengetahui didukung dengan rendahnya nilai $R$-squared kecepatan terjadinya keseimbangan dalam yakni sebesar 0.091320, artinya dalam jangka model. Nilai koefisien tersebut biasa disebut dengan speed of adjustment atau koefisien dari pendek kemampuan variabel bebas dalam mempengaruhi Indeks Saham Syariah Indonesia resid(-1). Namun perlu dipahami bahwa untuk hanyalah sebesar $9.13 \%$.

menjadikan model ECM sebagai prediksi dalam

Pada persamaan model dengan menganalisis kecepatan tingkat terjadinya variabel terikat ISSK, nilai ECT (residual) keseimbangan, nilai koefisien ECT tersebut adalah -0.113914 dengan nilai probabilitas harus bertanda negatif dan signifikan. Jika nilai $0.0188<0.05$. Nilai koefisien ECT bertanda ECT sudah memenuhi persyaratan tersebut, negatif dan signifikan secara statistik berarti dapat dikatakan bahwa spesifikasi model valid, bahwa model spesifikasi ECM yang digunakan dan dilanjutkan dengan pengujian hipotesis dalam penelitian ini valid. Nilai koefisen ECT serta menentukan hubungan variabel dalam sebesar -0.113914 mempunyai makna bahwa jangka pendek dan jangka panjang. $-0.113914 \%$ dari ketidaksesuaian yang dapat

Berdasarkan Tabel 5, hasil estimasi dikoreksi jangka pendek terhadap jangka ECM menunjukkan bahwa seluruh variabel panjang disesuaikan dalam waktu selama 11 bebas memiliki nilai prob lebih besar dari nilai bulan.

Tabel 5. Hasil Estimasi ECM

\begin{tabular}{lcccc}
\hline \multicolumn{5}{c}{ Variabel Terikat: ISSK } \\
\hline \multicolumn{1}{c}{ Variabel Bebas } & Coefficient & Std. Error & t-Statistic & Prob. \\
\hline C & 0.005416 & 0.004802 & 1.127730 & 0.2645 \\
D(INFLASI) & -0.007070 & 0.006773 & -1.043799 & 0.3013 \\
D(ln Kurs) & 0.181206 & 0.216139 & 0.838378 & 0.4056 \\
D(BI_RATE) & -0.027739 & 0.021743 & -1.275803 & 0.0276 \\
D(ln_HMMD) & -0.000298 & 0.011136 & -0.026745 & 0.9788 \\
ECT & -0.113914 & 0.085584 & 1.331012 & 0.0188 \\
\hline Prob (F-Statistic) & & 0.091320 & \\
R-squared & & 0.390050 & \\
\hline
\end{tabular}


Analisis Pengaruh Inflasi terhadap variabel kurs dalam jangka pendek seeprti Indeks Saham Syariah Indonesia. Pada ditunjukkan pada hasil estimasi ECM adalah penelitian ini hasil dari data disebutkan bahwa memliki pengaruh positif tetapi tidak signifikan dalam jangka pendek dan jangka panjang, terhadap Indeks Saham Syariah Indonesia. Telah inflasi berpengaruh negatif dan tidak signfikan dibahas sebelumnya bahwa saham syariah lebih pada derajat 5\%, namun pada derajat 10 kuat terhadap krisis dan gejolak fundamental persen, variabel inflasi berpengaruh signifikan. ekonomi sehingga apresiasi ataupun depresiasi Jika digunakan tingkat kepercayaan 5 persen, kurs tidak mempengaruhi Indeks Saham Syariah maknanya bahwa inflasi tidak mempengaruhi Indonesia.

pergerakan Indeks Saham Syariah Indonesia (ISSI). Hasil ini parallel dengan hasil penelitian Pasaribu \& Firdaus (2013) yang menyatakan inflasi yang relatif rendah (rata-rata inflasi Indonesia sebesar 5,42\%) dianggap bukan sebagai hambatan berinvestasi di Indonesia.

Hasil penelitian lainnya juga menyebutkan bahwa saham-sahan Syariah lebih perkasa dalam membendung guncangan krisis serta gejolak ekonomi seperti inflasi. Selain itu, saham syariah juga dinilai lebih mampu untuk pulih lebih cepat setelah dihantam krisis dibandingkan saham konvensional, sehingga variabel inflasi tidak berpengaruh terhadap Indeks Saham Syariah Indonesia (Beik \& Indeks Saham Syariah Indonesia. Hasil Fatmawati, 2014).

Analisis Pengaruh Kurs terhadap jangka pendek maupun jangka Panjang, BI Indeks Saham Syariah Indonesia. Perilaku Rate memiliki signifikan dan negatif terhadap 
Indeks Saham Syariah Indonesia. Hasil tersebut didukung oleh penelitian Beik \& Fatmawati (2014) yang menyebutkan bahwa investor akan berperilaku cenderung memilih instrumen investasi dengan return yang tetap dan berisiko rendah (misalnya deposito) dibandingkan pasar saham. Hal tersebut menunjukkan bahwa investor berperilaku rasional, dan ini merupakan karakteristik investor pada saham Syariah.

Analisis Pengaruh Harga Minyak Mentah Dunia terhadap Indeks Saham Syariah Indonesia. Dalam jangka pendek, hasil estimasi ECM menunjukkan bahwa harga minyak mentah dunia tidak berpengaruh signifikan terhadap Indeks Saham Syariah Indonesia. Hal tersebut dikarenakan saham syariah memang lebih kuat dalam menghadapi krisis dan gejolak fundamental ekonomi makro serta gejolak harga minyak mentah dunia.

Dalam jangka panjang, harga minyak mentah dunia berpengaruh signifikan dan negatif terhadap Indeks Saham Syariah Indonesia. Hasil tersebut didukung oleh penelitian yang dilakukan Ardana (2016) yang menyebutkan bahwa ketika suatu negara dikategorikan sebagai pengimpir minyak, maka adanya fluktuasi harga minyak mentah dunia akan membuat perekonomian menjadi rentan. Melihat kondisi tersebut, seorang investor akan berfikir rasional dalam berinvestasi, khususnya investasi di komoditas minyak. Di pasar saham, terjadinya fluktuasi pada harga minyak akan memberikan dampak pada saham-saham dengan yang bahan bakunya berbasis impor dan saham bank serta properti. Beruntungnya, perusahaan yang terdaftar di ISSI tidak didominasi oleh perusahaan produsen minyak. Oleh karena itu, fluktuasi minyak memberikan pengaruh berbeda pada Indeks Saham Syariah Indonesia.

\section{SIMPULAN DAN SARAN}

Model ECM mampu menjelaskan perilaku berbagai variabel yang digunakan dalam penelitian untuk memprediksi Indek saham Syariah Indonesia, namun dengan besaran dan arah yang berbeda. Pertama, naiknya kurs dan harga minyak mentah dunia akan menurunkan Indeks Saham Syariah Indonesia. Kedua, dalam jangka panjang dan jangka pendek kenaikan BI Rate akan menaikkan Indeks Saham Syariah Indonesia. Ketiga, naiknya tingkat inflasi tidak mempengaruhi Indeks Saham Syariah Indonesia.

Saran yang dapat dijadikan pertimbangan 
bagi pelaku pasar modal adalah diharapkan berperilaku rasional dalam menanggapi perubahan makroekonomi sebagai dasar dalammemutuskan berinvestasi pada pasar modal Syariah. Hal tersebut penting mengingat sensitivitas indeks saham sangat dipengharuhi oleh perilaku rasional investor dalam berinvestasi. Sementara bagi pemerintah diharapkan dapat terus menjaga stabilitas makroekonomi supaya memberi ketenangan bagia semua pelaku pasar modal di Indonesia.

\section{REFERENSI}

Ardana, Yudhistira. (2016). Pengaruh Variabel Makroekonomi Terhadap Indeks Saham Syariah Di Indonesia: Model ECM. Esensi: Jurnal Bisnis Dan Manajemen, 6(1), 17-28.

Beik, I. S., \& Fatmawati, S. W. (2014). Pengaruh Indeks Harga Saham Syariah Internasional dan Variabel Makro Ekonomi Terhadap Jakarta Islamic Index. Al-Iqtishad: Jurnal Ilmu Ekonomi Syariah, 6(2), 155-178. https:// doi.org/10.15408/aiq.v6i2.1228

Hamrita, M. E., \& Trifi, A. (2011). The Relationship between Interest Rate, Exchange Rate and Stock Price: A Wavelet Analysis. International Journal of Economics and Financial Issues, 1(4), 220-228. Retrieved from http:// www.econjournals.com/index.php/ijefi/ article/view/47/0

Malini, H., \& Jais, M. (2014). The Volatility of Indonesia Shari'ah Capital Market Stock Price Toward Macro Economics Variable. Indonesian Capital Market Review, 6(2), 63-72. https://doi/ org/10.21002/icmr.v6i2.3588

Pasaribu, R. B. F., \& Firdaus, M. (2013). Analisis Pengaruh Variabel
Makroekonomi Terhadap Indeks Saham Syariah Indonesia. Jurnal Ekonomi \& Bisnis, 7(2), 117-128. Retrieved from https://rowlandpasaribu.files. wordpress.com/2013/10/jeb-vol-7-no2-jul-2013-analisis-pengaruh-variabelmakroekonomi-terhadap-indeks-sahamsyariah-indonesia.pdf

Robert, A. (1997). Buku Pintar Pasar Modal Indonesia (The Intelligent Guide to Indonesian Capital Market). Jakarta: Mediasoft Indonesia.

Syahrir. (1995). Analisis Bursa Efek. Jakarta: PT Gramedia Pustaka Utaama.

Tandelilin, E. (2001). Analisis Investasi dan Manajemen Portofolio. Yogyakarta: BPFE.

Tandelilin, E. (2010). Portofolio dan Investasi Teori dan Aplikasi (Edisi 1). Yogyakarta: Kanisius IKAPI.

Thaker, M. A. B. M. T., Rohilina, W., Hassama, A., \& Amin, M. F. Bin. (2009). Effects of Macroeconomic Variables on Stock Prices in Malaysia: An Approach of Error Correction Model Retrieved from https://ideas.repec.org/p/pra/ mprapa/20970.html

Vejzagic, M., \& Zarafat, H. (2013). Relationship Between Macroeconomic Variables and Stock Market Index: Co-Integration Evidence From FTSE Bursa Malaysia Hijrah Shariah Index. Asian Journal of ManagementSciences \& Education, 2(4), 94-108. Retrieved from http://www. ajmse.leena-luna.co.jp/ajmsevol2n4.php

Widoatmodjo, S. (2005). Cara Sehat Investasi di Pasar Modal. Jakarta: PT. Jurnalindo Aksara Grafika. 


\section{Lampiran:}

\section{Hasil Uji Stasioneritas Residl}

Null Hypothesis: ECT has a unit root

Exogenous: Constant

Lag Length: 0 (Automatic - based on SIC, maxlag=10)

\begin{tabular}{lccc}
\hline \hline & t-Statistic & Prob. ${ }^{*}$ \\
\hline \hline Augmented Dickey-Fuller test statistic & -3.587124 & 0.0089 \\
\hline Test critical values: & 1\% level & -3.546099 & \\
& $5 \%$ level & -2.911730 & \\
& $10 \%$ level & -2.593551 & \\
\hline \hline
\end{tabular}

*MacKinnon (1996) one-sided p-values.

Kesimpulan: Stasioner di level

\section{Hasil Uji Stasioner pada Derajat Level}

Null Hypothesis: LN_ISSI has a unit root

Exogenous: Constant

Lag Length: 0 (Automatic - based on $\mathrm{SIC}$, maxlag=10)

\begin{tabular}{lccc}
\hline \hline & t-Statistic & \multicolumn{1}{c}{ Prob. ${ }^{*}$} \\
\hline \hline Augmented Dickey-Fuller test statistic & -0.770524 & 0.8199 \\
\hline Test critical values: & $1 \%$ level & -3.546099 & \\
& $5 \%$ level & -2.911730 & \\
& $10 \%$ level & -2.593551 & \\
\hline \hline
\end{tabular}

*MacKinnon (1996) one-sided p-values.

Null Hypothesis: INFLASI has a unit root

Exogenous: Constant

Lag Length: 1 (Automatic - based on SIC, maxlag=10)

\begin{tabular}{|c|c|c|c|}
\hline & & t-Statistic & Prob. \\
\hline \multicolumn{2}{|c|}{ Augmented Dickey-Fuller test statistic } & -1.918138 & 0.3219 \\
\hline Test critical values & $\begin{array}{c}1 \% \text { level } \\
5 \% \text { level } \\
10 \% \text { level }\end{array}$ & $\begin{array}{l}-3.548208 \\
-2.912631 \\
-2.594027\end{array}$ & \\
\hline
\end{tabular}

*MacKinnon (1996) one-sided p-values.

Null Hypothesis: LN_KURS has a unit root

Exogenous: Constant

Lag Length: 0 (Automatic - based on SIC, maxlag=10)

\begin{tabular}{lccc}
\hline \hline & t-Statistic & Prob. ${ }^{*}$ \\
\hline \hline Augmented Dickey-Fuller test statistic & -2.252128 & 0.1908 \\
\hline Test critical values: & 1\% level & -3.546099 & \\
& $5 \%$ level & -2.911730 & \\
& $10 \%$ level & -2.593551 & \\
\hline \hline
\end{tabular}

*MacKinnon (1996) one-sided p-values. 
Null Hypothesis: BI_RATE has a unit root

Exogenous: Constant

Lag Length: 0 (Automatic - based on SIC, maxlag=10)

\begin{tabular}{lccc}
\hline \hline & t-Statistic & Prob. ${ }^{*}$ \\
\hline \hline Augmented Dickey-Fuller test statistic & 0.280869 & 0.9754 \\
\hline Test critical values: & $1 \%$ level & -3.546099 & \\
& $5 \%$ level & -2.911730 & \\
& $10 \%$ level & -2.593551 & \\
\hline \hline
\end{tabular}

*MacKinnon (1996) one-sided p-values.

Null Hypothesis: LN_HMMD has a unit root

Exogenous: Constant

Lag Length: 1 (Automatic - based on SIC, maxlag=10)

\begin{tabular}{lccc}
\hline \hline & t-Statistic & Prob. ${ }^{*}$ \\
\hline \hline Augmented Dickey-Fuller test statistic & -2.458057 & 0.1310 \\
\hline Test critical values: & $1 \%$ level & -3.548208 & \\
& $5 \%$ level & -2.912631 & \\
& $10 \%$ level & -2.594027 & \\
\hline \hline
\end{tabular}

*MacKinnon (1996) one-sided p-values.

\section{Hasil Uji Stasioner pada Derajad First Difference}

Null Hypothesis: D(LN_ISSI) has a unit root Exogenous: Constant

Lag Length: 0 (Automatic - based on $\mathrm{SIC}$, maxlag=10)

\begin{tabular}{lccc}
\hline \hline & t-Statistic & Prob. ${ }^{*}$ \\
\hline \hline \multicolumn{2}{l}{ Augmented Dickey-Fuller test statistic } & -7.086454 & 0.0000 \\
\hline Test critical values: & $1 \%$ level & -3.548208 & \\
& $5 \%$ level & -2.912631 & \\
& $10 \%$ level & -2.594027 & \\
\hline \hline
\end{tabular}

*MacKinnon (1996) one-sided p-values.

Null Hypothesis: D(INFLASI) has a unit root

Exogenous: Constant

Lag Length: 0 (Automatic - based on SIC, maxlag=10)

\begin{tabular}{lccc}
\hline \hline & t-Statistic & Prob. ${ }^{*}$ \\
\hline \hline Augmented Dickey-Fuller test statistic & -5.854289 & 0.0000 \\
\hline Test critical values: & 1\% level & -3.548208 & \\
& $5 \%$ level & -2.912631 & \\
& $10 \%$ level & -2.594027 & \\
\hline
\end{tabular}

*MacKinnon (1996) one-sided p-values. 
Null Hypothesis: D(LN_KURS) has a unit root Exogenous: Constant

Lag Length: 0 (Automatic - based on SIC, maxlag=10)

\begin{tabular}{|c|c|c|c|}
\hline & & t-Statistic & Prob. $*$ \\
\hline \multicolumn{2}{|c|}{ Augmented Dickey-Fuller test statistic } & -6.185724 & 0.0000 \\
\hline Test critical values: & $\begin{array}{c}1 \% \text { level } \\
5 \% \text { level } \\
10 \% \text { level }\end{array}$ & $\begin{array}{l}-3.548208 \\
-2.912631 \\
-2.594027\end{array}$ & \\
\hline
\end{tabular}

*MacKinnon (1996) one-sided p-values.

Null Hypothesis: D(BI_RATE) has a unit root Exogenous: Constant Lag Length: 0 (Automatic - based on SIC, maxlag=10)

\begin{tabular}{lccc}
\hline \hline & t-Statistic & Prob. $^{*}$ \\
\hline \hline Augmented Dickey-Fuller test statistic & -6.045414 & 0.0000 \\
\hline Test critical values: & $1 \%$ level & -3.548208 & \\
& $5 \%$ level & -2.912631 & \\
& $10 \%$ level & -2.594027 & \\
\hline \hline
\end{tabular}

*MacKinnon (1996) one-sided p-values.

Null Hypothesis: D(LN_HMMD) has a unit root Exogenous: Constant Lag Length: 0 (Automatic - based on SIC, maxlag=10)

\begin{tabular}{lccc}
\hline \hline & t-Statistic & Prob. $^{*}$ \\
\hline \hline \multicolumn{2}{l}{ Augmented Dickey-Fuller test statistic } & -12.06255 & 0.0000 \\
\hline Test critical values: $\quad$ 1\% level & -3.548208 & \\
& $5 \%$ level & -2.912631 & \\
& $10 \%$ level & -2.594027 & \\
\hline \hline
\end{tabular}

*MacKinnon (1996) one-sided p-values. 


\section{Uji Kointegrasi}

Dependent Variable: LN_ISSI

Method: Least Squares

Date: 28/07/20 Time: 08:08

Sample: 2013M01 2017M12

Included observations: 60

\begin{tabular}{lrrrr}
\hline \hline \multicolumn{1}{c}{ Variable } & Coefficient & Std. Error & t-Statistic & Prob. \\
\hline \hline INFLASI & -0.012565 & 0.006711 & -1.872235 & 0.0665 \\
LN_KURS & 0.789750 & 0.223613 & 3.531765 & 0.0008 \\
BI_RATE & -0.052428 & 0.009220 & -5.686437 & 0.0000 \\
LN_HMMD & -0.041923 & 0.020078 & -2.088022 & 0.0414 \\
C & 8.174991 & 2.040140 & 4.007073 & 0.0002 \\
\hline \hline R-squared & 0.661898 & Mean dependent var & 14.88832 \\
Adjusted R-squared & 0.637308 & S.D. dependent var & 0.109010 \\
S.E. of regression & 0.065650 & Akaike info criterion & -2.529294 \\
Sum squared resid & 0.237048 & Schwarz criterion & -2.354765 \\
Log likelihood & 80.87881 & Hannan-Quinn criter. & -2.461026 \\
F-statistic & 26.91817 & Durbin-Watson stat & 0.481768 \\
Prob(F-statistic) & 0.000000 & & \\
\hline \hline
\end{tabular}

\section{Hasil Estimasi ECM}

Dependent Variable: D(LN_ISSI)

Method: Least Squares

Date: 28/07/20 Time: 08:19

Sample (adjusted): 2013M02 2017M12

Included observations: 59 after adjustments

\begin{tabular}{crrrr}
\hline \hline \multicolumn{1}{c}{ Variable } & Coefficient & Std. Error & t-Statistic & Prob. \\
\hline \hline D(INFLASI) & -0.007070 & 0.006773 & -1.043799 & 0.3013 \\
D(LN_KURS) & 0.181206 & 0.216139 & 0.838378 & 0.4056 \\
D(BI_RATE) & -0.027739 & 0.021743 & -1.275803 & 0.0276 \\
D(LN_HMMD) & -0.000298 & 0.011136 & -0.026745 & 0.9788 \\
ECT & -0.113914 & 0.085584 & -1.331012 & 0.1889 \\
C & 0.005416 & 0.004802 & 1.127730 & 0.2645 \\
\hline \hline R-squared & 0.091320 & Mean dependent var & 0.006644 \\
Adjusted R-squared & 0.005595 & S.D. dependent var & 0.036676 \\
S.E. of regression & 0.036574 & Akaike info criterion & -3.682830 \\
Sum squared resid & 0.070895 & Schwarz criterion & -3.471555 \\
Log likelihood & 114.6435 & Hannan-Quinn criter. & -3.600357 \\
F-statistic & 1.065273 & Durbin-Watson stat & 1.763009 \\
Prob(F-statistic) & 0.390050 & & \\
\hline \hline
\end{tabular}

